\title{
LOS ATAQUES CON AGENTES QUÍMICOS COMO FORMA DE VIOLENCIA EXTREMA CONTRA LAS MUJERES EN COLOMBIA*
}

\author{
Camila Alejandra Villalobos Araujo** \\ Recibido: Octubre 12 de 2017 \\ Aprobado: Noviembre 20 de 2017
}

\section{RESUMEN}

Teniendo en cuenta la relativa novedad del concepto de violencia extrema y del fenómeno de los ataques con agentes químicos, el presente texto pretende analizar los diferentes contextos desde los que puede ser vista la violencia extrema y los elementos que la describen, con el fin de articular dicho concepto al fenómeno de los ataques con agentes químicos. Es decir, se busca determinar y explicar por qué este tipo de ataques se configuran como un acto de violencia extrema, específicamente sobre las mujeres, en consideración de las historias y testimonios de las víctimas sobrevivientes de este flagelo en Colombia. A partir de ello, se pretende visibilizar la obligación del Estado de prevenir y reducir estos ataques, proponiendo soluciones a mediano y largo plazo, desde las tres ramas del poder público.

Palabras clave: Violencia extrema, ataques con ácido, mujeres, crueldad, prevención.

\footnotetext{
* Este artículo es resultado del proyecto de investigación "Reparación integral y justicia para las víctimas de ataques con agentes químicos", financiado por el Fondo de Extensión "FEX" de la Universidad del Rosario.

** Abogada y Joven Investigadora del Grupo de Derechos Humanos de la Facultad de Jurisprudencia de la Universidad del Rosario. E-mail:camila.villalobos@urosario.edu.co
} 


\title{
ATTACKS WITH ACID AS A FORM OF EXTREME VIOLENCE AGAINST WOMEN IN COLOMBIA
}

\begin{abstract}
The concept of extreme violence and the phenomenon of acid attacks are relatively new in the world context. This text aims to analyze the different contexts from which the extreme violence can be seen and the elements that describe it, in order to articulate this concept to the phenomenon of acid attacks. In other words, the text seeks to determine and explain why such attacks are configured as an act of extreme violence, specifically on women, taking into account the stories and testimonies of surviving victims in Colombia. From it, the text seeks to make visible the obligation of the State to prevent and reduce these attacks, proposing solutions in the medium and long term, from the legislative, judicial and executive power.
\end{abstract}

Keywords: Extreme violence, acid attacks, women, cruelty, prevention.

\section{ATAQUES COM AGENTES QUÍMICOS COMO UMA FORMA DE EXTREMA VIOLÊNCIA CONTRA AS MULHERES NA COLÔMBIA}

\section{RESUMO}

Tendo em conta a relativa novidade do conceito de violência extrema e do fenômeno dos ataques com agentes químicos, este texto pretende analisar os diferentes contextos a partir dos quais a violência extrema pode ser vista e os elementos que a descrevem, a fim de articular dito conceito ao fenômeno dos ataques com agentes químicos. Ou seja, procura determinar e explicar por que esses tipos de ataques são configurados como um ato de violência extrema, especificamente sobre as mulheres, levando em conta as histórias e testemunhos das vítimas sobreviventes deste flagelo na Colômbia. A partir disso, pretende tornar visível a obrigação do Estado de prevenir e reduzir estes ataques, propondo soluções a médio e longo prazo, desde os três ramos do poder público.

Palavras-chave: violência extrema, ataques de ácido, mulheres, crueldade, prevenção. 


\section{INTRODUCCIÓN}

La violencia ha sido un patrón de conducta que ha caracterizado a las sociedades humanas desde sus inicios. La búsqueda de poder, dinero, recursos, la conquista de territorios, entre otros factores, ha suscitado las guerras más cruentas y destructivas a lo largo de la historia. Así mismo, la violencia se ve materializada en nuestra vida cotidiana a partir de pequeños conflictos entre vecinos, colegas, amigos y familiares. En este marco toma lugar la violencia de género e intrafamiliar, tan antigua como la historia misma. No obstante, sólo hasta finales del siglo pasado empezó a darse una sensibilización respecto de dicha violencia: empezó a percibirse como un asunto que concierne al Estado y a la sociedad, y no como un asunto privado.

En cierto sentido, se puede decir que estamos "acostumbrados" a la violencia, ya que todos los días se refleja en nuestra sociedad y la vemos como algo "aceptable", hasta cierto punto. Sin embargo, cuando se sobrepasa el límite de aceptación de la violencia, es cuando hablamos de violencia extrema.

La violencia extrema se ha manifestado durante muchos años en múltiples formas, pero es en la actualidad cuando le hemos dado esta connotación de "extrema". Este tipo de violencia ha tenido sus más fuertes expresiones en situaciones como el holocausto nazi, la guerra étnica entre los tutsis y los hutus, la guerra en la antigua Yugoslavia, las masacres de los paramilitares en el conflicto colombiano, las dictaduras en Suramérica y otros miles de conflictos alrededor del mundo.

Teniendo en cuenta este contexto de violencia, es importante comprender el concepto de violencia extrema dentro de la categoría de violencia de género y con ello, entender la forma en que los actos por medio de los cuales la violencia se vuelve 'extrema', se encuentran profundamente ligados a los ataques con ácidos contra las mujeres.

\section{PROBLEMA DE INVESTIGACIÓN}

De acuerdo con lo anterior, es menester preguntarse ¿Qué sucede cuando la violencia extrema se da en ámbitos cotidianos, alejados de conflictos armados? ¿Qué sucede cuando las víctimas de la violencia extrema en la cotidianidad son mujeres? ¿Qué sucede cuando el rostro de una mujer es desfigurado por un agente químico? ¿Ello también puede ser considerado un acto de violencia extrema? 


\section{HIPÓTESIS DE TRABAJO}

El texto pretende abordar y responder las anteriores cuestiones con el fin de demostrar que los ataques con agentes químicos a las mujeres son una forma de violencia extrema debido a las consecuencias que representan para ellas estos ataques y a las características de los mismos.

\section{ESTRATEGIAMETODOLÓGICA}

Con el fin de responder las cuestiones planteadas inicialmente, se hizo una revisión de literatura acerca del concepto de violencia extrema, sus elementos y contextos, así como sobre el concepto, elementos y consecuencias de los ataques con ácido. De igual forma, se tuvieron en cuenta testimonios e historias de víctimas de ataques con ácido en Colombia y, se analizaron reportajes y crónicas periodísticas sobre este fenómeno.

Finalmente, se llevó a cabo una búsqueda de recomendaciones de entidades nacionales e internacionales y Organizaciones No Gubernamentales $(\mathrm{ONG})$ sobre la prevención y reducción de la violencia de género, específicamente de los ataques con ácido. A partir de la información recopilada se busca generar propuestas y soluciones que puedan incidir en los tomadores de decisiones del Estado, especialmente en el caso colombiano.

\section{DISCUSIÓN Y RESULTADOS}

En primer lugar, es menester definir los conceptos que se van a abordar a lo largo del texto y, así mismo, analizar sus contextos y las diferentes formas en que han sido estudiados.

\section{a) Violencia extrema}

La violencia y sus distintas manifestaciones son una condición prevalente en situaciones que no constituyen formalmente conflictos armados: pueden ser reuniones o manifestaciones, disturbios internos o estados de excepción; sin embargo, la violencia también se evidencia en los conflictos armados propiamente definidos, que pueden ser nacionales, internacionales e internacionalizados. (Arcaute Velazquez, García Nuñez, Noyola Vilallobos, Espinoza Mercado, \& Rodríguez Vega, 2015)

En el curso de estos eventos también pueden presentarse los llamados "actos de violencia extrema" que son consecuencia de las condiciones económicas, políticas y sociales del mundo actual. De igual forma, la 
terminología social especializada en la materia comprende dos conceptos de este tipo de actos, (i) cualitativo: que se refiere a las atrocidades que pueden venir aparejadas con el acto de violencia, y que algunos autores han llamado "crueldad"; y (ii) cuantitativo: referente a la destrucción de varios elementos humanos o materiales de una población, no directamente implicada en los conflictos. (Arcaute Velazquez, García Nuñez, Noyola Vilallobos, Espinoza Mercado, \& Rodríguez Vega, 2015)

Los actos de violencia extrema tienen también una gran trascendencia en los ámbitos urbano, gubernamental y militar. En las urbes, debido a la pobreza, las diferencias ideológicas y el desorden social, es frecuente oír que se han gestado actos de violencia extrema como enfrentamientos entre sectas, grupos o comunidades segregadas. Por otro lado, en el entorno gubernamental, la contienda entre las señaladas sectas, grupos o comunidades con las autoridades locales o estatales, tiene el potencial de derivar en actos de violencia extrema; además, la adquisición ilegal de armamento y el crimen organizado se encuentran involucrados en una gran proporción de ellos. En la arena militar, no hay duda de que la naturaleza propia de los conflictos armados acarrea, en su esencia, actos de violencia extrema. (Arcaute Velazquez , García Nuñez, Noyola Vilallobos, Espinoza Mercado, \& Rodríguez Vega, 2015)

De igual forma, el término de violencia extrema se aplica en contextos variados que se caracterizan por la ira, la furia, el odio, las masacres y la crueldad, en los que se intenta explicar la negación de la humanidad del otro al que se extermina(Osorio, 2005).

La realidad de la violencia extrema implica tanto la destrucción total de los seres humanos, como las destrucciones parciales y los ataques a la integridad física y moral de las personas. El calificativo "extremas", según Osorio (2015) se refiere a una,

"Forma de acción específica, un fenómeno social particular que parece situarse en un más allá de lo concebible y lo aceptable de la violencia." Esto es, "una categoría de crímenes no solo particularmente graves, sino también diferentes en cuanto a su significado en el campo de las otras prácticas de la violencia".

\section{b) Crueldad}

La crueldad es un concepto que suele confundirse con el de violencia extrema; sin embargo, son ideas diferentes que tienen líneas paralelas. Es decir, la crueldad es un ingrediente adicional al concepto de violencia extrema. 
La violencia revela la delgada línea que existe entre violencias extremas y prácticas de crueldad, cuando la violencia sobrepasa su propio objetivo, la destrucción física del otro, para volverse fuente de disfrute para el verdugo. Esto se traduce en la negación de toda humanidad de las víctimas, siendo frecuentemente cargadas de mitos, temores y amenazas, percibidas y entrelazadas con creencias y aspiraciones profundas. Si la violencia está siempre vinculada a una fractura destructiva, productora de mayor o menor sufrimiento, la crueldad añade la intención de hacer sufrir, y esto se traduce en deshonra y degradación al dolor de la víctima(Osorio, 2005).

La crueldad se ejerce en un escenario donde conviene demostrar que se le puede hacer sufrir al otro en su carne, que el otro no es un ser humano a la "imagen de Dios", sino un cuerpo animal desprovisto de derechos. No es que las prácticas de crueldad sean nuevas (los recuerdos de los regímenes fascistas alemán, argentino, chileno o indonesio no pueden borrarse), pero estas parecen cambiar de sentido y alcance, porque no se dirigen sólo a un adversario político, sino a la gente marcada por su propio origen o género(Osorio, 2005).

La crueldad tiene una funcionalidad. Detrás de las apariencias de la "violencia por la violencia", la crueldad más extrema puede remitir a significados que tienen sentido. Por ejemplo, las mutilaciones que afectan los ojos, la boca y los órganos sexuales suelen ser profundamente simbólicas y cargadas de sentido. Lo que buscan es entregar un mensaje a la víctima y a la sociedad: un mensaje que puede significar que el otro no vale, que no es un ser humano, que si no cumple con ciertos roles, sufre consecuencias, etc.(Wieviorka, 2003).

De acuerdo con lo anterior, la crueldad debe ser considerada desde un objetivo: su efecto mínimo es el terror del que se cree amenazado. El terror sustituye al consentimiento, produce una dependencia que liga a las víctimas del terror a su tirano. Asimismo, la crueldad produce una transformación eficaz sobre el cuerpo del enemigo y sobre sus opciones. El cuerpo humano constituye un espacio sagrado que el crimen de crueldad toca: no es solamente destructible y mortal, sino que es un objeto privilegiado del crimen de profanación. Por ello, el odio político, étnico o de género es la fuente energética crucial sin la cual las prácticas de crueldad serían inimaginables(Osorio, 2005).

\section{c) Violencia sobre los cuerpos}

Teniendo en cuenta los conceptos de violencia extrema y de crueldad, puede decirse que la violencia llevada al extremo no obedece a la pura 18 
necesidad de quitar la vida, sino que se centra en la destrucción del cuerpo marcado por el simbolismo de crueldad, como forma de atentar contra la dignidad y la condición humana. Para esta violencia y el simbolismo de crueldad sobre los cuerpos de las víctimas, la muerte no es suficiente, ya que el horror busca trascender la muerte, prolongando la deshumanización(Castro, 2016).

El cuerpo es visto como un discurso social y, junto con la mente y el espíritu, un elemento constitutivo de lo humano, por ende, su desaparición, tortura, mutilación y desmembramiento verifica la desarticulación psicológica y social de la condición humana, convirtiendo el cuerpo del cadáver en un mensaje deshumanizante del horror social (Castro, 2016).

Según la antropóloga Rita Laura Segato (2010), en su obra Las estructuras elementales de la violencia, el agresor, la víctima y la sociedad a la que pertenecen, comparten el mismo lenguaje e imaginario simbólico sobre el género. Por ello, la violación y el abuso sobre el cuerpo son comprendidos como un discurso social, una interacción comunicativa que resalta el hecho de que el agresor ejerce el poder soberano y de dominación; así, "la víctima es expropiada del control sobre su espacio-cuerpo"(Segato, 2010).

De acuerdo con lo anterior, en dicha relación agresor/soberanovíctima/dominada, existe: "Un acto de manipulación forzada del cuerpo del otro que desencadena un sentimiento de terror y humillación" (Segato, 2010). Pero este acto de sometimiento y terror no va dirigido únicamente contra la víctima, sino contra todos los que comparten la vida cotidiana con ella, incluso para quienes forman parte de estructuras y lazos más generales, pero igualmente compartidos: desde la familia y amigos, pasando por las personas con quienes comparte las rutinas de su vida cotidiana en diferentes ámbitos, hasta la sociedad e incluso el Estado (Segato, 2010).

Respecto al proceso de deshumanización, Hannah Arendt (2007) desarrolla tres momentos claves. El primer paso en el camino hacia la dominación total es matar en el hombre a la persona jurídica; esto se logra cuando a ciertas personas o grupos sociales se les deja fuera de la protección de la ley y se acepta la ilegalidad como su forma de vida. Significa entonces, que pierden todo derecho humano, incluidos la vida y la libertad. En este sentido, quedan fuera del reconocimiento jurídico de su existencia y comienzan a convertirse en parias humanos. 
El segundo paso es el asesinato de la persona moral en el hombre. Esto puede comprenderse como la corrupción de la solidaridad humana, en donde el sentido de la otredad se desintegra, lo que trae como consecuencia que "cuando ya no quedan testigos, no puede haber testimonio". Es la muerte de lo humano en cuanto ser social y constituye el principio de la muerte ontológica(Arendt, 2007).

El tercer paso tras el asesinato de la persona moral y el aniquilamiento de la persona jurídica, es la destrucción de la individualidad, la cual casi siempre tiene éxito. Es la culminación de la muerte ontológica, con la cual todo aspecto de lo humano, de ser del hombre, se pierde, y quedan solamente cuerpos reducidos a biología pura, a un estado de indefensión. El asesinato de esos entes desposeídos de su individualidad se convierte entonces en un acto meramente banal, pero profundamente marcado por un simbolismo de crueldad(Arendt, 2007).

Como consecuencia de este proceso, la violencia ontológica, además de constituir la culminación de la muerte de la persona jurídica, moral y de la individualidad, es, asimismo, la muerte/negación del cuerpo como entidad biológica, como ser vivo y como cuerpo humano. Así, el cuerpo se constituye en un vehículo de la degradación, denigración, negación de la vida; como una hoja sobre la que se escribe el discurso del horror con el uso de la mutilación, la flagelación y la tortura como símbolos de dominio y control soberano; como manifestación extrema del poder, incluso en un extremo denigrado(Castro, 2016).

De igual forma, el cuerpo es condensación de la existencia y la moral, por lo que su destrucción, más allá del acto de quitar la vida, constituye el acto más radical de la deshumanización, porque a su vez implica denigración del espíritu, represión de las emociones, destrucción del otro: el cuerpo mutilado queda reducido a pura indefensión (Castro, 2016).

Teniendo en cuenta este análisis, la violencia extrema es definida como una violencia ontológica en el sentido de que es una violencia llevada a los límites, es la expresión de la desmesura y la locura social, en donde la violencia se convierte en un fin absoluto. La violencia ontológica es el exceso del horror, el dolor llevado a sus extremos, la soberanía como dominio absoluto sobre la voluntad del otro. No hay posibilidad de dignidad, de mantener un punto posible de la condición humana; es llevar lo humano a sus límites y sobrepasarlos, mutilarlos, silenciarlos, torturar todo lo que contenga un rastro de lo potencialmente humano. Hoy el horror es un simple mensaje sobre los cuerpos de las víctimas(Castro, 2016). 


\section{d) Causas yelementos de la violencia extrema}

Desde un punto de vista psicológico, la violencia extrema gira en torno a emociones negativas reprimidas sobre los individuos que la cometen; emociones que se transforman en ira y combinaciones de ira con la satisfacción de hacer daño. Según Jonathan H. Turner, la violencia extrema es el resultado de varias fuerzas que convergen: la capacidad neuronal de los humanos para experimentar y expresar un rango de emociones de gran intensidad; la experiencia de la vergüenza en esferas institucionales y la represión de esa vergüenza; la intensificación y transmutación de estas emociones reprimidas en variantes de ira; la atribución de experiencias negativas a factores externos, y la carga de emociones positivas en rituales de interacción dirigidos a infligir daños a enemigos externos.(Turner, 2007)

Teniendo en cuenta esto y siguiendo a Turner (2007), las principales causas y elementos de la violencia extrema son los siguientes:

(i) La violencia es impulsada por una intensa incitación de emociones negativas contra los "enemigos", quienes son percibidos como los responsables de privaciones experimentadas por los miembros de una subpoblación.

(ii) Las variaciones en las emociones también tienen elementos de miedo y tristeza, lo que produce una mezcla más compleja de emociones negativas.

(iii) La violencia extrema, así mismo, es impulsada por variantes de satisfacción y felicidad mezcladas con ira (y tal vez miedo y tristeza), que producen al individuo placer al infligir o pensar en infligir daño a sus "enemigos". La violencia extrema casi siempre es impulsada por deseos de venganza.

(iv) Las emociones que conducen a la violencia extrema son sostenidas por redes de individuos que experimentan emociones positivas, a partir de rituales de interacción que cargan la solidaridad grupal y los símbolos grupales mediante la ventilación de agravios, la planificación de acciones y la ejecución real de violencia contra los "enemigos".

(v) La violencia extrema se esfuerza por mantener identidades en varios niveles: identidades de roles dentro de densas redes en las que los rituales de interacción generan excitación positiva; identidades sociales de los individuos como representantes de una categoría social que tiene agravios contra los miembros de otras categorías sociales. 
Lo anterior quiere decir que todos los seres humanos tenemos deseos y expectativas. Cuando dichos deseos y expectativas se cumplen, experimentamos emociones positivas, pero cuando no se cumplen o se reciben sanciones negativas ${ }^{1}$ por parte de otros, se empieza a experimentar un conjunto de emociones negativas que suelen ser reprimidas, lo que lleva a incurrir en actos de violencia extrema(Turner, 2007).

De igual forma, desde un punto de vista social, la violencia extrema y la crueldad no surgen en cualquier contexto; no se puede pensar que se ejerzan fácilmente, más que si reúnen un cierto número de condiciones, a saber: (Wieviorka, 2003)

(i) La impunidad: la impunidad es indispensable para la crueldad. Puede ser proporcionada por las circunstancias (ausencia de testigos), o aportada por las autoridades, que dejan hacer, que animan, o que incluso legitiman la transgresión en nombre de una autoridad, que es el Estado.

(ii) El miedo: el miedo es una "de-simpatía" que permite tratar al otro como un no-humano, y que puede empujar a las peores atrocidades producto del pánico.

(iii) La cultura del odio: ¿No están más presentes la crueldad y el sadismo en unas culturas que en otras, constituyendo entonces un terreno abonado tanto más favorable para su ejercicio cuanto la imagen del enemigo está claramente trazada en él? Según Goldhagen, citado en (Wieviorka, 2003), la violencia y la crueldad, no se basa en una cultura de obediencia sino de odio, que facilita y casi legitima la violencia gratuita.

(iv) La premeditación: generalmente existe una preparación para dichos actos de violencia.

Para concluir esta primera parte, se puede decir que los crímenes que implican actos de violencia extrema son puestos en escena como una ofensa intencional a la dignidad ontológica de la víctima. Con toda evidencia, la cuestión no es a quién matar, sino a quién deshumanizar, ensañarse sobre el cuerpo en cuanto cuerpo, destruyéndolo en su unidad simbólica y desfigurándolo(Cavarero, 2009).

Ahora que están claros los conceptos generales de violencia extrema y crueldad, es menester preguntarse ¿qué pasa cuando la víctima de los actos de violencia extrema es una mujer? ¿Qué pasa cuando la violencia extrema se ejerce por razón del género?

1 Como sanción negativa se entiende el castigar el incumplimiento de una norma. Al contrario de una sanción positiva, que se refiere a incentivar o premiar el cumplimiento de una norma. 
En términos generales, las relaciones de género se encuentran mediadas por la relación inseparable entre el ejercicio de poder y las formas dominantes de masculinidad, y tal poder se desenvuelve en distintas expresiones, como en el poder de protegerse a sí mismo y a los demás, así como en el poder atacar, en el poder sexual, intelectual y moral (Ibañez, 2014).

En muchas sociedades las mujeres deben cumplir con ciertos papeles dentro de la comunidad, y cuando no cumplen dichos roles o no se adecúan a estereotipos previamente creados, son víctimas de actos de extrema violencia. En ocasiones, la identidad individual de las mujeres es el principal motor de los ataques, cuando implica una amenaza para la masculinidad del hombre.

La crueldad, referida anteriormente, cuando se ensaña con las dimensiones corpóreas de las víctimas lo hace en una fragmentación del cuerpo, por cuanto ataca de diferentes maneras cada una de sus partes, y se eligen cuidadosamente las partes por violentar, dependiendo de lo que se quiera decir. Cuando la fragmentación del cuerpo se efectúa por medio de mutilaciones estratégicas, dicha metaforización política cobra un sentido aún más directo y descarnado. El sufrimiento intenso del cuerpo va acompañado de la dislocación de este como parte del ser, y se convierte en sí mismo en la metáfora de la deshumanización (Ibañez, 2014).

Existen diversas manifestaciones de violencia y crueldad contra la mujer en razón de su género, como el feminicidio, la violencia intrafamiliar, la violencia sexual, entre otras; sin embargo, existe una forma de violencia que era poco conocida, pero, en los últimos años, se ha venido intensificando de tal manera, que puede ser considerada como una forma de violencia extrema contra la mujer. Este tipo de violencia es el fenómeno de los ataques con agentes químicos, que se analizará a continuación.

\section{ATAQUES CONAGENTES QUÍMICOS}

Los ataques con agentes químicos se definen como el acto de lanzar ácido o una sustancia corrosiva similar en el cuerpo de otra persona, con la intención de desfigurarla, mutilarla, torturarla o matarla. Los perpetradores de estos ataques arrojan ácido usualmente al rostro de sus víctimas, quemándolo y dañando el tejido de la piel, a veces exponiendo y disolviendo los huesos. Los tipos más comunes de ácido usados en este tipo de ataques son el sulfúrico, el nítrico y el hidroclórico. Las consecuencias a largo plazo de estos ataques incluyen ceguera, 
cicatrices permanentes en cara y cuerpo, así como dificultades sociales, psicológicas y económicas(Bhullar, 2013).

\subsection{Efectos de los ataques con ácido:}

Según Bhullar (2013) existe una variedad de efectos sobre una víctima de ataque con ácido que se pueden clasificar de la siguiente manera:

(i) Efectos en la salud: el efecto más notable de un ataque con ácido es la desfiguración de cuerpo y cara de por vida. En consecuencia, la víctima se enfrenta a cambios físicos que requieren tratamientos y cirugías a largo plazo, así como a retos psicológicos que requieren una profunda intervención de consejeros en cada etapa de la recuperación física. Todos estos efectos impactan la viabilidad social, psicológica y económica de las comunidades.

(ii) Efectos médicos: la severidad del daño depende de la concentración del ácido y el tiempo antes de que el ácido sea removido con agua o neutralizado con un agente para tal efecto. El ácido puede carcomer rápidamente la piel, la capa de grasa debajo de la piel, y en algunos casos el hueso que está debajo. Los párpados y labios son completamente destruidos, la nariz y los oídos son severamente afectados. También existe el riesgo de septicemia ${ }^{2}$, falla renal, despigmentación e incluso la muerte.

(iii) Efectos psicológicos: se reportan altos niveles de ansiedad, depresión y baja autoestima.

(iv) Efectos sociales: además de los efectos médicos y psicológicos, existen muchas implicaciones sociales para los sobrevivientes de ataques con ácido, especialmente para las mujeres. Por ejemplo, estos ataques generalmente dejan a las víctimas en situación de discapacidad en algún sentido, porque dependen de su esposo o familia para realizar actividades cotidianas como comer, bañarse o hacer sus necesidades. Estas dependencias son incrementadas por el hecho de que las sobrevivientes no pueden encontrar un trabajo estable ni rentable. Esta negatividad impacta la viabilidad económica y causa conflictos en la familia que cuida de ellas.

Específicamente en Colombia existe un alto índice de ataques contra mujeres en los últimos años, lo que lleva a preguntarse ¿por qué tantas mujeres colombianas mueren o son atacadas de alguna forma por parte de sus esposos, novios o ex parejas? Aunque es una pregunta difícil de responder a primera vista, la cultura machista en Colombia y el conflicto armado pueden ayudar a proveer la respuesta. 
El machismo es un fuerte sentido de orgullo masculino o un exagerado sentido de poder y fuerza. En Latinoamérica este término es usado para describir una mirada desde la cual el rol de la mujer en el orden social es ser subordinada por el hombre(Jolin, 2016).

Respecto a los ataques con ácido en Colombia, estos crímenes generalmente son cometidos por parejas o ex parejas celosas o pretendientes rechazados, quienes arrojan sustancias corrosivas a la cara de las mujeres para dejarlas desfiguradas permanentemente. Como el feminicidio, los ataques con ácido son comunes en sociedades donde la impunidad y la misoginia ${ }^{3}$ son prevalentes. Por otro lado, la disponibilidad y la facilidad para conseguir los ácidos también contribuye a que aumenten los ataques (Jolin, 2016).

El primer ataque con ácido en Colombia fue reportado en 1996 y ahora se estima que hay un promedio de 100 casos por año. Hace un tiempo, la legislación colombiana clasificaba los ataques con ácido bajo la figura de "lesiones personales" (tipificada en el Código Penal), por lo cual las sanciones eran mínimas. Sin embargo, a partir del caso de Natalia Ponce de León, quien fue atacada con ácido en 2014 por Jonathan Vega, las cosas cambiaron para las víctimas de estas agresiones en el país.

Jonathan Vega es un hombre joven con quien Natalia se había visto solo dos veces, pero él se obsesionó con ella. Después de acosarla por meses, Vega llegó al edificio donde vivía la mamá de Natalia. Cuando Natalia bajó las escaleras hacia la recepción para preguntar quién estaba llamando al apartamento, Vega le arrojó ácido en la cara y huyó. En contraste con la poca atención que prestan a estos casos en las mujeres pobres, el Presidente Juan Manuel Santos ofreció una recompensa de aproximadamente 120 millones de pesos por información relacionada con el atacante, quien fue prontamente capturado.

Desde ese entonces, Natalia ha tenido 20 cirugías para recuperarse las heridas que quemaron su cara, brazos y abdomen. pesaren medio de todas las cirugías y tratamientos a los que ha sido sometida, ha liderado una campaña para que el Estado cumpla con su deber de prevención frente a los ataques con ácido y provea mayor cuidado médico a las víctimas que generalmente no tienen los recursos para pagar los tratamientos. Debido al trabajo incansable de Natalia, en enero de 2016 el presidente Santos firmó la Ley 1773, que incrementa las penas para quienes ataquen con ácido y garantiza a las víctimas el derecho a un tratamiento médico adecuado.(Jolin, 2016)

3 La misoginia es una actitud mediante la cual una persona demuestra odio o desprecio hacia el género femenino. 


\subsection{Los ataques con ácidos y la violencia extrema}

Ahora bien, teniendo en cuenta las características de la violencia extrema y el análisis realizado sobre los ataques con agentes químicos, es pertinente afirmar que una de las expresiones más fuertes de la violencia extrema contra la mujer es el fenómeno de los ataques con ácido.

Para explicar la anterior afirmación, es importante recordar algunas de las frases más significativas de las víctimas de ataques con ácido en Colombia: "Siento que me mataron, así este viva", "Cuando alguien comete un acto tan horripilante, me marca y destruye mi vida. Se lleva todo lo que significa ser un ser humano", "El acto de marcar o desfigurar la cara de una mujer es tratarla como a un objeto, una cosa, una propiedad privada", "Estos ataques con ácido son una brutal forma de mantener a las mujeres asustadas, y en muchos casos, funciona"(Weiss, 2014).

Estos sentimientos, expresados por mujeres víctimas sobrevivientes de ataques con agentes químicos en Colombia, resumen el significado de la violencia extrema. En el momento en que una mujer es atacada con un ácido, su vida se transforma de manera radical, como le sucedió a Yolima Sánchez, quien fue atacada el 19 de enero de 2014 por un hombre desconocido en la puerta de su casa en Cali, Valle del Cauca. En el momento en que Yolima sintió la sustancia en su rostro pensó que era agua caliente o alcohol, ya que no tuvo tiempo de entender qué pasaba; el $30 \%$ de su cuerpo resultó quemado, teniendo lesiones tan graves como la pérdida de su ojo derecho. Yolima es madre de dos hijos y lo que más le preocupaba no era lo que la sociedad pensara de ella, sino cómo sus hijos la verían, sentía temor de su rechazo. Antes del ataque, esta mujer vendía jugos en un puesto establecido en su ciudad, pero ahora no puede trabajar en la calle porque el sol, el viento y el polvo afectan su piel e impiden una recuperación satisfactoria. Nadie le ha brindado ayuda para conseguir un trabajo en el cual pueda estar en su casa; sin embargo, ella guarda la esperanza de obtener un empleo que la ayude a empezar de nuevo, a resurgir y a dignificar su vida. (Tiempo real, tiempo de verdad, 2014)

Las historias de Yolima y Natalia Ponce son las de muchas mujeres en Colombia y el mundo, mujeres que han sufrido estos actos atroces y se ajustan a las características de la violencia extrema referidas previamente. Los ataques con ácido no son casuales: son el resultado de una mezcla de emociones negativas como la ira, el miedo y el deseo de venganza contra una persona, generalmente una mujer, que es vista 26 
como "el enemigo", debido a un rechazo, una ruptura u otro conflicto interpersonal.

El objetivo del autor del crimen no es acabar con la vida de la mujer, sino destruirla y marcarla para siempre, como forma de dar un mensaje a la víctima y a la sociedad. Ese mensaje suele poner a la mujer en una posición de inferioridad y como un objeto o propiedad del atacante. Lo que se quiere decir es: "si no eres mía, no serás de nadie más". Por eso buscan desfigurar el rostro, que es el eje del cuerpo de una mujer.

Lo que hace que este tipo de violencia sea extrema es, por un lado, su objetivo de destruir a otra persona por su género, es decir, cuando una mujer no se adapta al rol que le corresponde tradicionalmente en la sociedad; por otro lado, al desfigurar partes específicas del cuerpo de una mujer, se agrega el elemento de la crueldad que niega toda humanidad, tratándola como a un objeto, como a un ente que carece de derechos. Además, se afecta no solo su integridad física sino su integridad moral, su espíritu, sus emociones y su autoestima: se le reduce a nada.

Adicionalmente, el autor del ataque busca que la víctima sea excluida de la sociedad, y generalmente lo consigue, porque una mujer que es atacada con ácido encuentra vulnerados la mayoría de sus derechos y esto le impide desarrollarse adecuadamente en sociedad.

Los derechos que más se vulneran después de un ataque con ácido son: (i) el derecho a la salud, porque generalmente los hospitales y centros de salud no saben cómo atender estos casos, lo que genera traumatismos y profundidad en las heridas; (ii) el derecho a la protección, porque a las víctimas no se les garantiza su integridad y seguridad personal cuando denuncian agresiones previas al ataque con ácido; (iii) el derecho al trabajo, debido a que la mayoría de víctimas pierden su empleo, si contaban con uno, o les es imposible conseguir uno, si no lo tenían; y (iv) el derecho de acceso a la justicia, ya que muchas veces las autoridades no reciben adecuadamente las denuncias, o no prestan la debida atención. (Fundación Natalia Ponce de León; Consultorio Jurídico Universidad del Rosario; Grupo de Acciones Públicas (GAP), 2017).

Eso es de lo que se trata la violencia extrema: de acabar con la vida de una persona sin necesidad de matarla, y esa es la consecuencia de un ataque de esta magnitud. Es por esto que los ataques con agentes químicos deben ser castigados con severidad. No son un crimen común y van más allá de lo "aceptable" por parte de la sociedad: no solo se lastima a una mujer físicamente, sino que se destruye por completo su vida, y se 
normalizan y perpetúan los estereotipos de género existentes en países como Colombia, donde la cultura del machismo es especialmente alta. Pero más importante que castigar estos crímenes, es prevenirlos. Por ello, el Estado, desde sus distintas ramas, está en la obligación de tomar acciones que minimicen este tipo de ataques, que cambien la cultura de odio y de venganza y que hagan recuperar la confianza en las instituciones por parte de las víctimas, para que ellas se atrevan a denunciar. Por ello, es menester brindar algunas recomendaciones sobre la manera como se podrían evitar este tipo de ataques en el largo plazo.

\section{ACCIONES A TENER EN CUENTA POR PARTE DE LOS ESTADOS:}

Los Estados están en la obligación de proteger los derechos de todas las personas. Esto implica prevención de delitos, de ataques y de violencia, castigos eficientes a quienes la justicia declare culpables de la comisión de un delito y protección a las víctimas de todo tipo de crímenes.

Los ataques con agentes químicos no pueden quedar excluidos de estas obligaciones. Por ello, ONU Mujeres (2012) ha publicado una serie de recomendaciones, para que cada Estado incluya en su legislación ciertos elementos que permiten prevenir y castigar estos ataques. Dichas recomendaciones son:

(i) La legislación debe sancionar a toda persona que cometa un ataque con ácido, incluidos los familiares de la víctima y las personas que colaboran con esta práctica nociva.

(ii) La legislación debe establecer penas de prisión, multas y penas de carácter educativo. Las directrices sobre imposición de las penas deben reflejar la gravedad del delito.

(iii) La legislación debe establecer el aumento de penas si la víctima muere como consecuencia del ataque.

(iv) La legislación debe exigir que los vendedores de ácidos estén autorizados para ello.

(v) La legislación debe tipificar como delito la venta de ácidos sin autorización.

(vi) La legislación debe exigir a los vendedores de ácidos, la creación y el mantenimiento de un registro de cada venta y de la identidad del comprador.

(vii) La legislación debe imponer a los prestadores de servicios médicos, la obligación de informar a los responsables de hacer cumplir la ley, de todos los casos de lesiones corporales causadas por ácido. 
(viii) La legislación debe ordenar a las autoridades competentes que investiguen todos los casos de lesiones corporales causadas por ácido, comunicadas por prestadores de servicios de salud.

(ix) La legislación debe establecer y financiar campañas de sensibilización de la opinión pública y formación para todos los sectores sobre esta práctica nociva y sus consecuencias.

(x) Deben modificarse o derogarse las leyes y otras prácticas, como los crímenes cometidos en nombre del "honor", que perpetúan estas prácticas nocivas.

(xi) La legislación debe permitir que las víctimas puedan solicitar un recurso civil contra sus agresores, la indemnización por daños y perjuicios debe incluir el coste de la cirugía reconstructiva.

(xii) La legislación debe establecer servicios médicos, jurídicos y otros tipos de rehabilitación para las víctimas.

Algunas de estas recomendaciones se encuentran incluidas en la Ley 1773 de 2016 (Ley Natalia Ponce),(Congreso de la República, 2016) en la cual se crea el tipo penal de 'Lesiones con agentes químicos, ácido y/o sustancias similares', se aumentan las penas para los agresores y se regula la venta de estas sustancias. Sin embargo, todavía es necesario trabajar para prevenir estos ataques y disminuir la impunidad, una vez perpetrados. Por ello, siguiendo a Bhullar (2013), las recomendaciones que se hacen al respecto son las siguientes:

(i) Prevención: muchos reportes han resaltado la necesidad de incrementar el rol legal de las ONG's para ofrecer apoyo a los sobrevivientes. Adicionalmente, se destaca la necesidad de una regulación más estricta en cuanto a la venta de ácidos, con el fin de combatir esta problemática social. De igual forma, es necesario crear una o varias políticas públicas referentes a la prevención de estos ataques, para evitar que se conviertan en un problema de salud pública y también con el objetivo de crear conciencia sobre este fenómeno en todos los sectores de la sociedad.

(ii) El rol de las ONG's: las Organizaciones no Gubernamentales proveen servicios de rehabilitación para los y las sobrevivientes mientras actúan como abogados para una reforma social, esperando incrementar el apoyo y el conocimiento de estos ataques. Por ello, es necesario apoyar el trabajo de la sociedad civil, otorgándoles espacios de participación e incidencia.

(iii) Tratamiento: los tratamientos médicos para las víctimas suelen ser inadecuados en muchos países en vía de desarrollo donde la incidencia es alta. Además, las consecuencias psicológicas de los ataques suelen ser ignoradas y no son atendidas por los 
profesionales de la salud. Por ende, se considera de vital importancia atender no solo las lesiones físicas, sino también los traumas psicológicos que enfrenta la víctima. Para ello, también pueden practicarse ejercicios que ayuden a recuperar su confianza y autoestima.

(iv) Género: las mujeres tienen un alto riesgo de ser atacadas con ácido en ciertos países como Bangladesh e India. Otro factor que pone a las víctimas en riesgo de este tipo de ataques es su estatus socioeconómico, ya que las que viven en pobreza son más propensas a ser atacadas. Los ataques con ácido suelen ser conocidos como "crímenes pasionales", impulsados por celos y venganza; sin embargo, este término es erróneo ya que estos casos deben ser tratados como un asunto de género, dado que son el resultado de la rabia que produce que una mujer se atreva a ir en contra de los roles que le impone la sociedad.

(v) Impunidad: además de los procedimientos médicos inadecuados, muchas víctimas no reportan los ataques a las autoridades, debido a una falta de confianza en ellas y un sentido de desesperanza por la impunidad que se presenta y el miedo a las represalias. Por ello, es menester que las autoridades sigan adecuadamente los procesos de recepción de denuncias y juzguen debidamente estos casos e inviertan suficiente tiempo y energía para lograr una sentencia justa.

\section{CONCLUSIONES}

Después de estudiar y analizar detenidamente el concepto de violencia extrema y su relación con el fenómeno de ataques con agentes químicos, se puede concluir que la violencia extrema es definida como la serie de actos que sobrepasan el nivel de 'aceptación' que tiene la sociedad sobre la violencia, negando toda humanidad de las víctimas, cosificándolas y reduciéndolas a la nada con el fin de destruir su integridad física y moral.

La crueldad es un ingrediente adicional de los actos de violencia extrema y tiene como función otorgar un mensaje a la víctima y a la sociedad. Generalmente es un mensaje cargado de sentimientos de superioridad y deseos de dominación.

Las causas de la violencia extrema son de diferente índole. Las causas psicológicas se resumen en represión de emociones negativas como ira, miedo y deseo de venganza. Desde el punto de vista socio-económico, los actos de violencia extrema suelen producirse por falta de cultura, pobreza social y económica e impunidad sobre los crímenes cometidos. 
Los actos de violencia extrema también son ejercidos como una forma de violencia de género, ya que el agresor, la víctima y la sociedad, comparten el mismo lenguaje e imaginario simbólico sobre el género. Por ello, las agresiones sobre el cuerpo son comprendidas como un discurso social de soberanía y dominación sobre la mujer.

Debido a las características de la violencia extrema, se puede concluir que los ataques con agentes químicos son una manifestación de dicha violencia, ya que en el momento en que una mujer sufre este tipo de ataque, su condición de humanidad y de dignidad es destruida por completo. La víctima suele ser excluida de la sociedad, pierde su trabajo, sus amigos e incluso sus familiares. Todo esto provocado por un deseo de venganza de parte del victimario, que no encuentra satisfechos sus deseos de dominación y soberanía sobre la mujer.

Los ataques con ácido, como forma de violencia extrema, deben ser castigados con severidad. Por ello, el Estado debe aumentar las penas contra los agresores y tener en cuenta distintas formas de re socialización y educación desde las cárceles para evitar la repetición de este tipo de crímenes. Adicionalmente, se debe regular la venta de estas sustancias químicas y trabajar en la reducción de los niveles de impunidad frente a estos delitos, ya que la falta de confianza frente a las instituciones hace que las víctimas no denuncien y, en consecuencia, los ataques aumenten de manera significativa.

Finalmente, el beneficio que se obtiene con el castigo a los agresores y la regulación de la venta de los ácidos no será suficiente si el Estado no considera acciones para prevenir estos ataques. El Estado está en la obligación de: (i) generar una cultura de tolerancia y de respeto, por medio de campañas de sensibilización frente a esta problemática; (ii) formular políticas públicas que obliguen a las instituciones estatales a trabajar sobre el tema, para evitar que este fenómeno se convierta en un problema de salud pública, y (iii) reducir el índice de ataques con agentes químicos en Colombia.

\section{REFERENCIAS BIBLIOGRÁFICAS}

Arcaute Velazquez, F. F., García Nuñez, L. M., Noyola Vilallobos, H. F., Espinoza Mercado, F., \& Rodríguez Vega, C. E. (2015). Mecanismos de lesión en actos de violencia extrema. Cirugía y Cirujanos, 257-262. 
Arendt, H. (2007 ). Los orígenes del totalitarismo. Ciudad de México: Taurus .

Bhullar, D. (2013). Acid Throwing: A cause of concern [Ataques con ácido: Una causa de preocupación]. Journal of Punjab Academy of Forensic Medicine \& Toxicology, 60-62.

Castro, L. J. (2016). La escritura del horror en los cuerpos: violencia ontológica y simbolismo de crueldad. Estudios Políticos, 57-80.

Cavarero, A. (2009). Horrorismo. Nombrando la violencia contemporánea (Saleta de Salvador Agra, trad.). Barcelona: Anthropos Editorial.

Congreso de la República. (06 de Enero de 2016). Ley 1773 de 2016. Ley Natalia Ponce. Bogotá, Cundinamarca, Colombia.

Fundación Natalia Ponce de León; Consultorio Jurídico Universidad del Rosario; Grupo de Acciones Públicas (GAP). (21 de Marzo de 2017). Cartilla Práctica Derechos de las Víctimas Sobrevivientes de Ataques con Agentes Químicos. Obtenido de http://www. urosario.edu.co/consultorio-juridico/Documentos/Cartilla SobrevivientesWeb.pdf

Ibañez, E. A. (2014). Feminización y subalternización del otro enemigo. Construcción y destrucción de corporalidades en contextos de conflicto armado y violencia extrema. Colombia Internacional, $57-82$.

Jolin, N. (2016). Gender-Based Violence in Colombia: New Legislation Targets Femicides and Acid Attacks [Violencia basada en género en Colombia: Nuevos objetivos legislativos en feminicidios y ataques con ácido]. Tulane Law Review, 371-371.

ONU Mujeres. (2012). Centro virtual de conocimiento para poner fin a la violencia contra mujeres y niñas. Obtenido de Ataques con ácido: http://www.endvawnow.org/es/articles/607-ataques-conacido.html

Osorio, A. (2005). Violencias extremas y etnicidad: la ex Yugoslavia. Alteridades, 75-84. 
Segato, L. R. (2010). Las estructuras elementales de la violencia. Ensayos sobre género entre la antropología, el psicoanálisis y los derechos humanos. Buenos Aires : Prometeo.

Tiempo real, tiempo de verdad. (14 de Julio de 2014). Tiempo real, tiempo de verdad. Obtenido de Yolima Sánchez/Víctima de ataque con ácido: https://www.youtube.com/watch?v=5V01WrqL2DY

Turner, J. H. (2007). Self, emotions and extreme violence: Extending symbolic interationist theorizing [Uno mismo, las emociones y la extrema violencia: Extendiendo la teorización interaccionista simbólica]. Symbolic Interaction, 501-530.

Weiss, J. (2014). Women's rights in Colombia: acid attacks on the rise [Derechos de las mujeres en Colombia: ataques con ácido en aumento]. World Affairs , 50-57.

Wieviorka, M. (2003). Violencia y crueldad (M. Escamilla, trad.). Anales de la cátedra Francisco Suárez, 155-171. 